\title{
Nonlinear elasto-plastic formulation for tunneling effects on superstructures
}

\author{
Elkayam, Itai; Klar, Assaf
}

Published in:

Canadian Geotechnical Journal

Link to article, DOI:

$10.1139 /$ cgj-2018-0021

Publication date:

2019

Document Version

Early version, also known as pre-print

Link back to DTU Orbit

\section{Citation (APA):}

Elkayam, I., \& Klar, A. (2019). Nonlinear elasto-plastic formulation for tunneling effects on superstructures. Canadian Geotechnical Journal, 56(7), 956-969. https://doi.org/10.1139/cgj-2018-0021

\section{General rights}

Copyright and moral rights for the publications made accessible in the public portal are retained by the authors and/or other copyright owners and it is a condition of accessing publications that users recognise and abide by the legal requirements associated with these rights.

- Users may download and print one copy of any publication from the public portal for the purpose of private study or research.

- You may not further distribute the material or use it for any profit-making activity or commercial gain

- You may freely distribute the URL identifying the publication in the public portal

If you believe that this document breaches copyright please contact us providing details, and we will remove access to the work immediately and investigate your claim. 


\section{Canadian Geotechnical Journal}

\section{Nonlinear elasto-plastic formulation for tunneling effects on superstructures}

\begin{tabular}{|r|l|}
\hline Journal: & Canadian Geotechnical Journal \\
\hline Manuscript ID & cgj-2018-0021.R2 \\
\hline Manuscript Type: & Article \\
\hline Aute Submitted by the & 23 -Aug-2018 \\
\hline $\begin{array}{r}\text { Complete List of Authors: } \\
\text { Keyword: }\end{array}$ & $\begin{array}{l}\text { Elkayam, Itai; Technion Israel Institute of Technology Faculty of Civil and } \\
\text { Klar, Assaf; Technion Israel Institute of Technology Faculty of Civil and } \\
\text { Environmental Engineering; Technical University of Denmark, Civil } \\
\text { Engineering }\end{array}$ \\
\hline $\begin{array}{r}\text { Is the invited manuscript for } \\
\text { consideration in a Special } \\
\text { Issue? : }\end{array}$ & \begin{tabular}{l} 
Not applicable (regular submission) \\
\hline
\end{tabular} \\
\hline
\end{tabular}

\section{SCHOLARONE ${ }^{\text {m }}$ \\ Manuscripts}




\title{
Nonlinear elasto-plastic formulation for tunneling effects on superstructures
}

\author{
Itai Elkayam and Assaf Klar
}

\begin{abstract}
The paper presents a formulation for evaluating the effect of tunneling on existing buildings. The formulation involves the matrix condensation method to represent the response of a linear elastic building and macro-elements to represent the nonlinear elasto-plastic soil behavior. The formulation includes new features that allow interaction between macro-elements, both through the soil continuum and the structure, to result in the final displacements of the foundations due to tunneling. One of the advantages of the formulation is its ability to incorporate a general input of a greenfield field displacement for the interaction analysis, allowing consideration of various tunneling scenarios. The formulation is evaluated by a comparison to a continuum based solution obtained using the finite difference method. The formulation is then used to conduct a parametric analysis of tunneling-soil-superstructure interaction, considering three different approaches: (1) the suggested elasto-plastic formulation, (2) purely elastic analysis, and (3) simplified analysis in which the foundations are forced to displace as the greenfield. It is shown that the vertical settlements of the foundations, due to tunneling, are the greatest when the first approach is considered. This is an outcome of the combined vertical and horizontal yielding, depicted in the formulation by the coupled yield function and plastic flow potential. Yet damage, which relates to differential settlement, appears to be smaller in the elasto-plastic formulation.
\end{abstract}

Key words: Tunneling, Building settlements, Macro-Elements, Soil-Structure interaction.

\section{Introduction}

The evaluation of tunneling effects on existing structures is an important process that engineers need to confront when dealing with the construction of new tunnels in congested urban areas. When dealing with buried structures, such as pipelines, the characteristics of the considered structure may be

Itai Elkayam. Department of Structural Engineering and Construction Management, Faculty of Civil and Environmental Engineering, Technion- Israel Institute of Technology, Haifa 32000, Israel.

Assaf Klar. ${ }^{1}$ Department of Civil Engineering, Technical University of Denmark, 2800 Kgs., Lyngby, Denmark. On a sabbatical leave from the Technion - Israel Institute of Technology.

${ }^{1}$ Corresponding author (e-mail: klar@technion.ac.il). 
easily defined by longitudinal bending and axial stiffnesses, facilitating the development of a holistic solution for engineering use (e.g. Klar 2018; Klar et al. 2016; Klar and Marshall 2015). On the other hand, obtaining a representative solution for the effect of tunneling on existing buildings may raise difficulties, due to the complexity of modeling both the structure and the soil accurately, and the fact that the solution requires the input from two different civil engineering disciplines (i.e. geotechnical and structural engineering). Consequently, most of the existing solutions and design procedures involve simplified representation of buildings as beams (e.g. Attewell et al. 1986; Burland 1995; Potts and Addenbrooke 1997), which may fail to depict the intricate force displacement relations which exist in the buildings.

A more detailed integrated analysis aiming to understand the response of the structure was performed by Giardina et al. (2015 2013) to study the nonlinear response of masonry buildings to tunneling induced displacements. Franza et al. (2017) presented an integrated analysis of framed structures on pile foundations, where the soil was modeled using Winkler springs, and Franza and DeJong (2018) presented an analysis of framed structures on shallow foundations that includes linear elastic soil response together with gap and slippage formation at the foundation soil interface.

While integrated analysis involving both structure and soil should be advocated for, it is of interest to develop a procedure that would allow a division of tasks between the two disciplines, yet results in a unified accurate solution. This paper follows the concepts of matrix condensation, limited to linear elastic structures, for collaboration between structural and geotechnical engineers, and offers a complete framework for the solution of tunneling effects on superstructures including nonlinear soil behavior.

The consideration of soil nonlinearity is achieved by adopting and extending the concepts of macroelements, previously used for deformation evaluation of single shallow foundations under static and cyclic external loading (e.g. Butterfield and Gottardi 1994; Gottardi et al. 1999; Houlsby and Cassidy 2002; Nova and Montrasio 1991).

The paper is composed of four main sections. Section 2 presents the suggested formulation. Section 3 validates the formulation against continuum based solutions. Section 4 presents a parametric analysis aiming at identifying the advantages of the suggested approach. Section 5 discusses the main conclusions of the current work. 


\section{Formulation}

A popular trend, in recent years, has been to rely on greenfield displacements as an input to soilstructure interaction analyses, rather than using finite element (FE) or finite difference (FD) methods for a complete solution. The reason for this trend is that finite element or finite difference solutions fail to provide reasonable predictions of greenfield displacements unless advanced constitutive relationships are used (Addenbrooke et al. 1997; Franzius et al. 2005; Mair and Taylor 1997), and therefore, their general use for the solution of the interaction problem may be problematic. The use of the greenfield displacements as an input for the analysis may be considered one of the key advantages of the suggested method which avoids the difficulties that arise when using FE or FD methods. Nonetheless, a reliable description of greenfield displacements is still required for the effective use of the method. This may be obtained by field measurements of greenfield displacements near the location of the structure, but sufficiently distant such that the tunneling does not affect the building. In the event that site-based measurement of greenfield displacements is not a feasible option or if an analysis must be performed at an early stage of the project, one may rely on empirical relationships for the greenfield input, such as Mair et al. (1993), Loganathan and Poulos (1998) and Marshall et al. (2012).

The formulation presented in this section focuses on the interaction between the structure, the soil, and the tunnel, without an emphasis on a specific macro-element model. The formulation assumes that a macro-element, which represent the reaction of the soil to foundation movements, involves a yield function, $f$, a plastic flow potential, $g$, and a hardening law, $H$, formulated within a generalized strain space as described in Muir-Wood (2004).

The formulation is based on the following four assumptions: (1) the structure is linear elastic; (2) the structure is in contact with the soil at all times; (3) the tunnel itself is not affected by the structure; (4) plasticity due to building loads may develop only locally around the foundations. Note that slippage between the foundation and the soil is not considered separately from the horizontal yielding (i.e. no interface elements). The first assumption is legitimate if the main purpose of the analysis is to identify the range of tunneling conditions for which the structure remains in its serviceability state (i.e. no serious damage and stiffness degradation). The second assumption is mostly likely valid for any multistory buildings (due to their large overall weight). Regardless, the validity of the first two assumptions may be examined during, or at the end of, the evaluation process. The third and fourth 
assumptions may be less legitimate. However, if the foundations are sufficiently spaced and the tunnel is deep, these assumptions may be sufficient, and allow the use of an elasto-plastic macro-elements formulation for the foundation system. Note that assumptions (3) and (4) do not restrict the development of a plastic region around the tunnel, which is most likely to develop regardless of the building, but merely assumes a separation of plastic zones. This is because the plasticity around the tunnel itself is depicted in the greenfield response (which constitutes an input to the analysis). If, however, a large tunnel volume loss is expected and the plastic zone around the tunnel extends up to the surface, it is recommended to avoid the use of the proposed method, since the above assumptions are violated. The need for separation of plastic zones (between the tunnel and the structure) was discussed in Klar et al. (2007) for the problem of tunneling effects on pipelines.

Macro-element formulations (Muir-Wood 2004; Nova and Montrasio 1991) aim to represent individual foundations, without considering any interaction between the different foundations which form the global foundation system. The current work, on the other hand, assumes coupling between foundations, through both the response of the structure and the continuum nature of the soil. This, however, complicates the mathematical treatment involved with macro-elements, as the plastic multiplier for a certain foundation becomes dependent on the behavior of the other foundations. To avoid the complex process of solving the resulting nonlinear set of equations, an iterative scheme, which allows local solution of the macro-elements is adopted. The following lines present the governing expressions involved in the formulation, some of which are solved globally for the complete foundation system, and some individually for each foundation.

The superstructure behavior may be represented using the following equation:

[1] $\quad\left\{F^{c}\right\}=\left[S^{c}\right]\left\{u^{f}\right\}-\{R\}$

where $\left\{F^{c}\right\}$ is a vector representing the soil reaction acting on the superstructure, $\left\{u^{f}\right\}$ are the total displacements of the foundations (3 for translation and 3 for rotation), $\left[S^{c}\right]$ is the condensed stiffness matrix of the superstructure associated with the foundation's nodes, and $\{R\}$ are the fixed support reactions of the structure (i.e. the live and dead loads of the building transferred to a fixed foundation system). The condensed matrix $\left[S^{c}\right]$ may easily be derived by the structural engineer from the complete building model, facilitating the aforementioned task division between the engineers. The condensed 
matrix is built by restraining all of the degrees of freedom of all foundations, and then imposing a unit displacement at each degree of freedom at a time. The calculated reactions at all of the restraints provide the values for a single column of the condensed matrix. This procedure is repeated for all the degrees of freedom to result in a relatively small, fully populated, condensed matrix that incorporates the structural response within a lean representation of the foundation system. This condensation approach was recently used for incorporating the structure response in a foundation optimization problem (Leung et al. 2017).

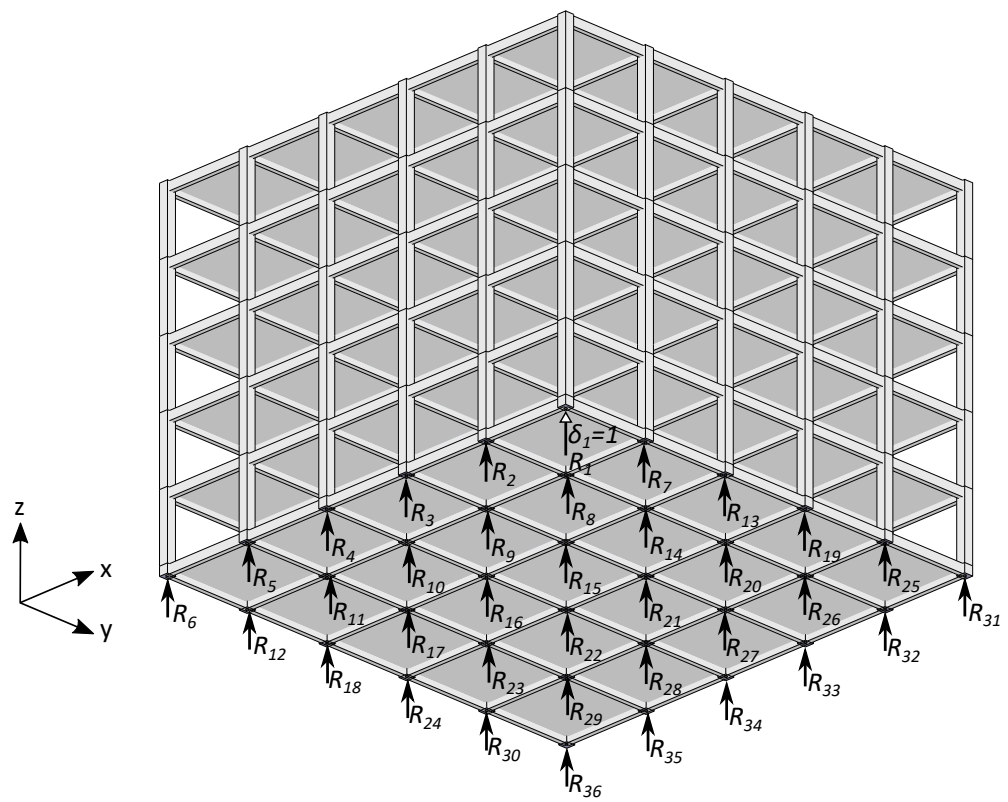

Fig. 1. Illustration of the matrix condensation method. A view from bottom up of the foundation reactions

An illustration of the process is provided in Fig. 1 for a simplified case in which the foundations resist only vertical displacements. A unit displacement is imposed in the vertical direction of foundation No. $1\left(\delta_{1}=1\right)$. The resultant reactions in all of the foundations, $R_{i}$, constitute the first column of the condensed stiffness matrix $\left(S_{i, 1}^{c}=R_{i}, i=1, . ., N\right.$, where $N$ is the number of foundation degrees of freedom, 36 in the example). This process of imposing a displacement and calculating the reactions needs to be repeated for all other foundations to result in $S_{i, j}^{c}$ for the $N$ by $N$ condensed matrix. The above condensation process, limited for vertical response in the illustration, should be performed for all degrees of freedom involved in the soil structure coupling.

The above refers to the response of a linear elastic structure. The other component of the formu- 
lation is the response of the soil. In general, the soil displacement, represented by vector $\left\{u^{s}\right\}$, may be decomposed into two main components; one due to local loading (loading at the location of the foundation), $\left\{u^{l}\right\}$, and the other due to loading at other locations (including the tunnel), $\left\{u^{c}\right\}$.

[2] $\quad\left\{u^{s}\right\}=\left\{u^{l}\right\}+\left\{u^{c}\right\}$

Essentially $\left\{u^{c}\right\}$ are the displacements resulting from the continuum nature of the soil domain, which is actually the reason for the interaction between the foundations (themselves) and the tunnel. $\left\{u^{c}\right\}$ may be further decomposed into two terms, one expressing the effect of the tunnel and the other expressing the interaction between the foundations:

[3] $\quad\left\{u^{c}\right\}=\left\{u^{\text {tun }}\right\}+\left\{u^{i t}\right\}$

where $\left\{u^{t u n}\right\}$ are the continuum displacements due to tunneling, and $\left\{u^{i t}\right\}$ are the displacements due to the interaction between different foundations. Utilizing the aforementioned third assumption, that the structure does not affect the tunnel, leads $\left\{u^{t u n}\right\}$ to be equal to the greenfield displacements, $\left\{u^{g f}\right\}$. Following the fourth assumption, stating that plastic deformations due to building loads develop locally around the foundation, $\left\{u^{l}\right\}$ is decomposed into elastic and plastic components, leading Eq. 2 to be:

[4] $\quad\left\{u^{s}\right\}=\left\{u^{l e}\right\}+\left\{u^{l p}\right\}+\left\{u^{g f}\right\}+\left\{u^{i t}\right\}$

The soil reaction can be represented as a linear function of the local elastic displacements:

$$
\left\{F^{s}\right\}=\left[K^{s}\right]\left\{u^{l e}\right\}=\left[K^{s}\right]\left(\left\{u^{s}\right\}-\left\{u^{l p}\right\}-\left\{u^{g f}\right\}-\left\{u^{i t}\right\}\right)
$$

where $\left\{F^{s}\right\}$ are the soil forces acting on the foundation, and $\left[K^{s}\right]$ is the soil elastic stiffness matrix, which can be established based on elastic continuum solutions as detailed later on.

In order to establish a soil-structure interaction solution one must ask for equilibrium and compatibility between the soil and the structure. That is, the forces acting on the foundations are equal but opposite to the forces acting on the soil $\left(\left\{F^{c}\right\}=-\left\{F^{s}\right\}\right)$, and $\left\{u^{f}\right\}=\left\{u^{s}\right\}$, which can be unified into a single displacement value, $\{u\}$. Substituting $\{u\}$ for $\left\{u^{f}\right\}$ in Eq. 1 and for $\left\{u^{s}\right\}$ in Eq. 5, and 
equating $\left\{F^{c}\right\}$ to $-\left\{F^{s}\right\}$ results, after some algebraic manipulation, in:

[6] $\left(\left[S^{c}\right]+\left[K^{s}\right]\right)\{u\}=\left[K^{s}\right]\left(\left\{u^{l p}\right\}+\left\{u^{g f}\right\}+\left\{u^{i t}\right\}\right)+\{R\}$

The assumption that plastic displacement is local infers that the interaction between the foundation is solely elastic. Consequently, $\left\{u^{i t}\right\}$ may be evaluated using a flexibility matrix:

[7] $\left\{u^{i t}\right\}=[\lambda]\left\{F^{s}\right\}=-[\lambda]\left\{F^{c}\right\}=-[\lambda]\left(\left[S^{c}\right]\{u\}-\{R\}\right)$

where $[\lambda]$ is the soil elastic interaction matrix, which relates the displacement at the foundation to the forces acting at other foundations. Note that $[\lambda]$ is fully populated, having a main diagonal of zeros. Introducing the above equation into Eq. 6 results in:

[8] $\left(\left[S^{c}\right]+\left[K^{s}\right]+\left[K^{s}\right][\lambda]\left[S^{c}\right]\right)\{u\}=\left[K^{s}\right]\left(\left\{u^{l p}\right\}+\left\{u^{g f}\right\}\right)+\left(\left[K^{s}\right][\lambda]+[I]\right)\{R\}$

Note that except for $\left\{u^{l p}\right\}$ and $\{u\}$, all other quantities are known or defined as part of the input to the problem (including the independent greenfield displacement). In fact, if $\left\{u^{l p}\right\}$ can be evaluated then the foundation displacement solution, $\{u\}$, may be easily obtained from the solution of the above linear set of equations. The process of resolving $\left\{u^{l p}\right\}$ involves the use of macro-elements, together with their yield and plastic flow functions.

Since the solution of a macro-element requires the evaluation of the forces on the foundation, and is force-path dependent, an incremental procedure is suggested. The procedure involves an iterative scheme to obtain the correct plastic increments without the need to formulate a set of nonlinear equations for simultaneous solution of all foundations. At each increment of loading, the following equation is solved iteratively to evaluate the increment of the total displacement of the foundations:

[9a] $\quad\left\{\Delta u_{I+1}\right\}=[A]^{-1}\left[K^{s}\right]\left(\left\{\Delta u_{I}^{l p}\right\}+\left\{\Delta u^{g f}\right\}\right)+[A]^{-1}[B]\{\Delta R\}$

$[9 \mathrm{~b}] \quad[A]=\left[S^{c}\right]+\left[K^{s}\right]+\left[K^{s}\right][\lambda]\left[S^{c}\right]$

$[9 \mathrm{c}] \quad[B]=\left[K^{s}\right][\lambda]+[I]$

where $\left\{\Delta u_{I}\right\}$ represents the incremental displacement of the foundation at iteration "I". Only if the 
increment of plastic displacement, $\left\{\Delta u_{I}^{l p}\right\}$, is zero, the process will converge after a single iteration, otherwise the plastic displacement for each foundation needs to be evaluated iteratively.

The values of $\left\{\Delta u_{I}\right\}$ and $\left\{\Delta u_{I}^{l p}\right\}$ are updated in the iterative process until convergence to the correct values, based on the yield function and plastic flow potential. The calculation of the plastic displacement is conducted locally for each foundation, and then gathered together into a single vector to be evaluated within Eq. 9a in the next iteration. At every iteration the plastic displacement increment is evaluated using the following equation:

[10a] $\left\{\Delta u_{I+1}^{l p}\right\}=\Lambda \frac{d g}{d\left\{F^{*}\right\}}$

[10b] $\left\{\Delta u_{I+1}^{l e}\right\}=\left([I]+[\lambda]\left[S^{c}\right]\right)\left\{\Delta u_{I+1}\right\}-\left\{\Delta u_{I+1}^{l p}\right\}-\left\{\Delta u^{g f}\right\}-[\lambda]\{\Delta R\}$ [10c] $\Lambda=$ Solve $\left[f\left(\left[K^{s}\right]\left(\left\{u^{l e}\right\}+\left\{\Delta u_{I+1}^{l e}\right\}\right), H\left(\left\{u^{l p}\right\}+\left\{\Delta u_{I+1}^{l p}\right\}\right)\right)=0\right]$

$$
(\Lambda \geq 0)
$$

where $H$ is the hardening function, $\left\{u^{l e}\right\}$ and $\left\{u^{l p}\right\}$ are the total elastic and plastic displacements developed until the current increment, $\left\{F^{*}\right\}$ are the total forces acting on the ground at the start of the increment, $f$ and $g$ are the yield and plastic flow potential functions of the foundation macro-element formulation and $\Lambda$ is the plastic multiplier. In Eqs. 10a and 10c, $\left\{u^{l e}\right\},\left\{u^{l p}\right\}$ and $\left\{F^{*}\right\}$ are the local components for each foundation individually.

Because macro-elements are force path dependent the procedure should simulate also the construction stage of the building. This may be achieved by first simulating the response of the structure and the soil to the building loads, followed by the second stage of calculation aiming to simulate the response of the system to the tunnel excavation. In general, there is no difference in the formulation for the two stages, only that at the first stage $\{R\}$ is gradually increased while $\left\{u^{g f}\right\}$ is zero, followed by the second stage where $\{R\}$ is constant and $\left\{u^{g f}\right\}$ develops. Fig. 2 shows a flowchart of the iterative calculation cycle for a given increment of loading or excavation.

\section{Verification}

The formulation suggested in this paper is based on several assumptions which require validation. For example, the assumption of linear interaction between the foundations and the use of greenfield displacement as input for the solution. These assumptions relate to the continuum nature of the soil, and 


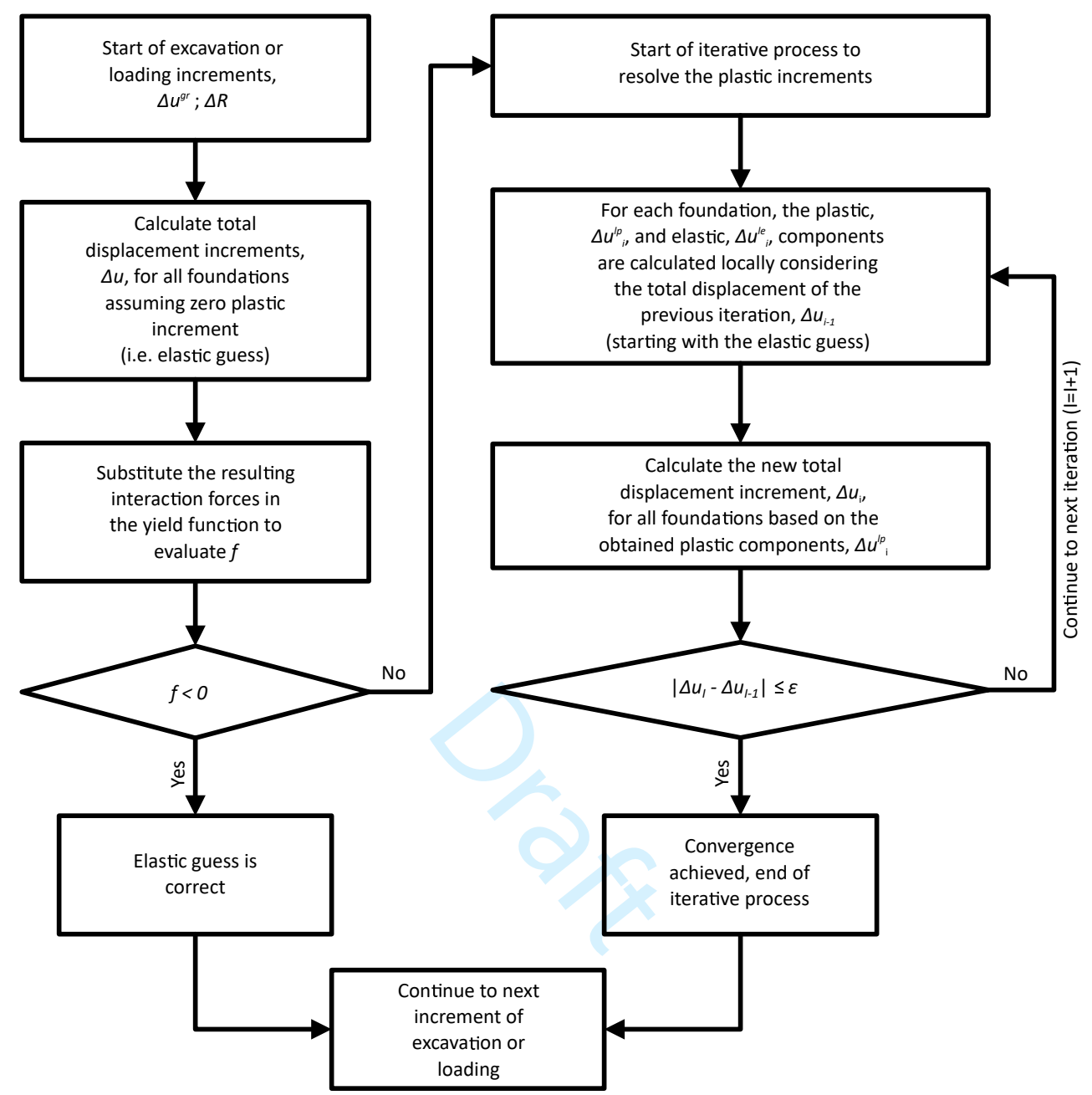

Fig. 2. Flowchart of the incremental iterative process

hence require validation against continuum based solutions. This work uses a FD solution merely to validate the fundamental assumptions, and does not claim that the continuum solutions necessarily represent any specific field condition (due to the aforementioned difficulties to predict reliable greenfield displacement using FD). Since the suggested formulation requires an input of the form of greenfield displacement, the limitation of the FD solution does not hinder the validity of the comparison, as long as both involve the same greenfield conditions. Consequently, the greenfield input used for the comparison is that obtained from the greenfield condition of the continuum (FD) solution. 


\subsection{Building model}

The building used for the verification is presented in Fig. 3. The considered building is a 5-story (6-floor) building with a $20 \times 20 \mathrm{~m}$ base. The building is composed of $0.4 \times 0.4 \mathrm{~m}$ columns, $0.2 \times 0.4 \mathrm{~m}$ beams and floor thickness of $0.16 \mathrm{~m}$. A C-20 concrete $\left(E_{c}=26.2 \times 10^{6} \mathrm{kPa}\right)$ is associated with the structural components. The height of each storey is $3 \mathrm{~m}$ and the distance between the columns is $4 \mathrm{~m}$. The building is supported by $36,2.5 \times 2.5 \mathrm{~m}$, shallow foundations, all of which are rigid and connected to the structure by a short $0.4 \mathrm{~m}$ column extension. Fig. 4 shows the foundations footprint together with its numbering. A uniform load on each floor of $5 \mathrm{kN} / \mathrm{m}^{2}$ was considered in addition to the self weight of the building. The building model, from which the condensed stiffness matrix and reactions vector (reactions with no displacement of the foundations) were extracted, was generated using the structural engineering package of COMSOL Multiphysics (COMSOL 2008). The extracted $\left[S^{c}\right]$ and $\{R\}$ were used as an input both for the formulation and the FD continuum model.

While the formulation is general and may include up to 6 degrees of freedom for coupling between the soil and structure, the torsional one may be released at the level of the soil, under the assumption that the structure resistance to torsion is high compared to that of the soil and that the greenfield input does not include torsional components. This assumption was considered in the problems presented in the paper, and hence only 5 degrees of freedom are coupled ( 3 translations in $x, y$, and $z$, and 2 rotations about $x$ and $y$ axes).

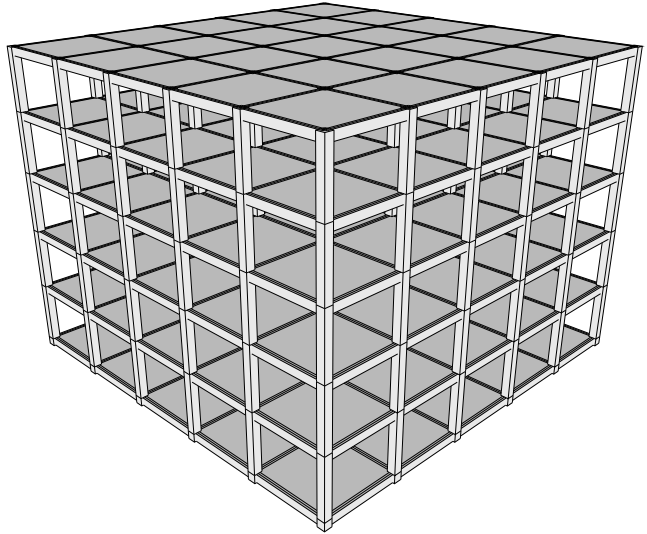

Fig. 3. Building model used for the verification process. 


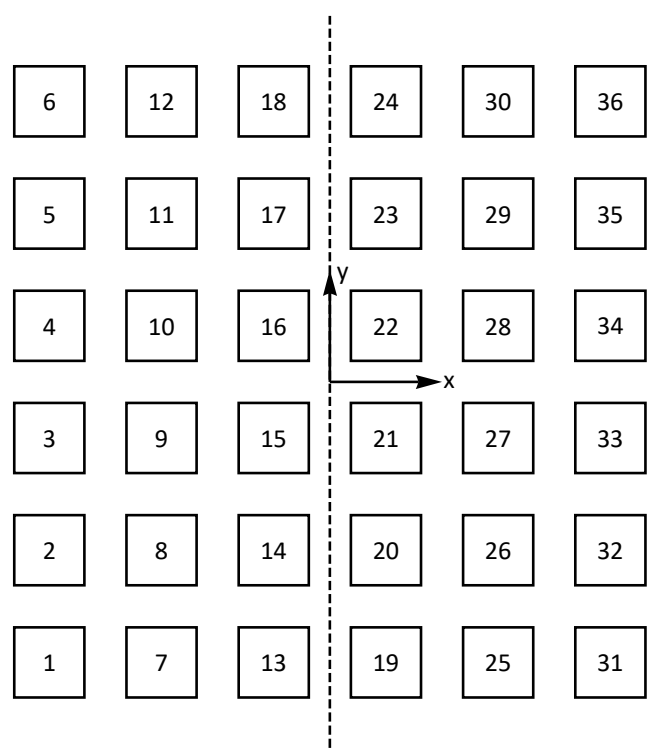

Fig. 4. Foundations position and numbering

\subsection{Finite difference model}

The finite difference model used for the verification is shown in Fig. 5. The FLAC ${ }^{3 D}$ (Itasca 2011) code was used to solve the equations of motion. The soil was modeled using an elasto perfectly plastic constitutive law answering the Mohr-Coulomb yield criterion and non-associative plastic flow. The soil was modeled using a bulk modulus, $K$, of $83,333 k P a$, shear modulus, $G$, of $50,000 k P a$, internal angle of friction, $\phi$, of $35^{0}$, cohesion, $c$, of 0 , mass density, $\rho$, of $1.7 t / \mathrm{m}^{3}$, and a plastic flow potential of zero dilation $\left(g=\sigma_{1}-\sigma_{3}\right)$. The mesh size in the model (i.e. the distance between two neighboring grid points) was $0.5 \mathrm{~m}$ in each direction.

A designated subroutine was written to represent the building behavior using the established $\left[S^{c}\right]$ matrix. The building was modeled by controlling the velocity of the grid points which are in contact with the structure foundations (represented in blue in Fig. 5). The motion of each foundation was governed by a servo-control that answers the following expression:

$$
\{v\}_{i}^{t+\Delta t / 2}=\{v\}_{i}^{t-\Delta t / 2}+\frac{\{\Delta F\}_{i}-0.8\left|\{\Delta F\}_{i}\right| \operatorname{sgn}\left(\{v\}_{i}^{t-\Delta t / 2}\right)}{\{M\}_{i}} \Delta t
$$

$$
\{M\}_{i}=\left[S^{c}\right]_{i, i} \cdot \Delta t^{2} \cdot F S
$$

where $\{v\}_{i}$ is the rate of change of the $i^{t h}$ degree of freedom (for example velocity and rotations), 
Fig. 5. View of the $\mathrm{FLAC}^{3 \mathrm{D}}$ model

$\{\Delta F\}_{i}$ is the unbalanced force between the structure and the soil at degree of freedom $i(\{\Delta F\}=$ $\left[S^{c}\right]\{u\}-\{R\}+\left\{F^{s}\right\}$, where $\left\{F^{s}\right\}$ is the sum of forces representing the soil reaction at the displacement controlled grid points). $\{M\}_{i}$ is the pseudo mass of each degree of freedom defined to keep the critical time step as that defined by FLAC $^{3 \mathrm{D}}$ together with a stability factor of safety, $F S$. Note that the above equation represents the "foundation" degrees of freedom and not those of the grid points associated with the contact area of the foundation in the FLAC $^{3 \mathrm{D}}$ (blue area in Fig. 5). That is, the 5 degrees of freedom of each foundation in the structure need to be converted into rigid body motion of a rectangular area representing the foundation in the continuum analysis.

$$
v_{g p, z}=v_{f, z}+v_{f, \theta x} \cdot\left(y_{g p}-y_{f}\right)+v_{f, \theta y} \cdot\left(x_{f}-x_{g p}\right)
$$$$
v_{g p, x}=v_{f, x}
$$$$
v_{g p, y}=v_{f, y}
$$

where $\left\{v_{f}\right\}$ is the foundation velocity and $\left\{v_{g p}\right\}$ is the grid point velocity ( $z$ refers to the vertical direction and $x$ and $y$ to the horizontal directions). The effective contact area of the foundation (considering Published by NRC Research Press 
the element size) was $2.5 \times 2.5 \mathrm{~m}$.

A $5 \mathrm{~m}$ diameter tunnel with a centerline depth of $15 \mathrm{~m}$ was considered. The tunnel excavation process was modeled by volume control, forcing the tunnel perimeter to contract concentrically towards the tunnel centerline. A volume loss of 1\% (at the tunnel level) was prescribed, yielding a maximum greenfield displacement of $6.96 \mathrm{~mm}$. As mentioned earlier, the purpose of the procedure is to validate the fundamental assumptions, given the same greenfield input. As such there is no claim that the considered simplified concentric contraction nor the resultant finite difference greenfield condition represent any specific field condition, but rather constitute a reasonable input for comparison between the methods. In fact, the resultant greenfield vertical displacements at the location of the foundations corresponded well to a Gaussian settlement trough with an inflection point, i, of $8.22 \mathrm{~m}$. This indicates that the considered case may represent a real tunnelling scenario, but of a tunnel at greater depth than $15 \mathrm{~m}$ (considering a typical ratio of $i / Z_{t}$ of 0.5 or smaller).

\subsection{Fitted fundamental functions}

In order to validate the suggested formulation with the FD code, the elasto-plastic behavior of a single foundation and the interaction between the foundations must be comparable before introducing them into the formulation. Consequently, the foundation elastic stiffness matrix $\left(\left[K^{s}\right]\right)$, the hardening function $H$, the interaction matrix $([\lambda])$ and the greenfield displacement $\left(\left\{u^{g f}\right\}\right)$, were all extracted from the FD model using different, independent, relevant simulations. The following subsections, 3.3.1 to 3.3.4, detail the determination processes of the individual functions, while section 3.4 summarizes the comparison of the suggested approach with that of FLAC ${ }^{3 \mathrm{D}}$.

\subsubsection{Single foundation loading}

The foundation elastic stiffness matrix and the hardening function (i.e. the limit vertical load) were defined using a finite difference simulation of a single foundation with the same soil properties as presented in section 3.2.

The foundation elastic stiffness matrix was defined using an elastic FLAC ${ }^{3 \mathrm{D}}$ model with the same elastic properties as in the elasto-plastic model. The stiffness matrix was evaluated by applying displacements to one of the foundations of the model (the corner foundation) and summing the related 
grid point unbalanced forces (reactions). The resultant foundation elastic stiffness matrix is:

$$
\begin{gathered}
\{F\}=\left[K^{s *}\right] \cdot\{u\} \\
\left(\begin{array}{c}
V \\
H_{x} \\
H_{y} \\
M_{x} / B \\
M_{y} / B
\end{array}\right)=\left(\begin{array}{ccccc}
K_{v v} & 0 & 0 & 0 & 0 \\
0 & K_{h h} & 0 & 0 & -K_{h \theta} \\
0 & 0 & K_{h h} & K_{h \theta} & 0 \\
0 & 0 & K_{h \theta} & K_{\theta \theta} & 0 \\
0 & -K_{h \theta} & 0 & 0 & K_{\theta \theta}
\end{array}\right) \cdot\left(\begin{array}{c}
u_{z} \\
u_{x} \\
u_{y} \\
B \theta_{x} \\
B \theta_{y}
\end{array}\right) \\
K_{v v}=37.38 \times 10^{4} \mathrm{kN} / \mathrm{m}, K_{h h}=32.89 \times 10^{4} \mathrm{kN} / \mathrm{m}, \\
K_{\theta \theta}=42.55 \times 10^{4} / B^{2} \mathrm{kN} / \mathrm{m}, K_{h \theta}=40.44 \times 10^{4} / B \mathrm{kN} / \mathrm{m}
\end{gathered}
$$

where $B$ is the foundation width, $\left[K^{s *}\right]$ is the elastic stiffness matrix for a single foundation. The soil elastic stiffness matrix, $\left[K^{s}\right]$, for all foundations is composed using the single foundation matrix.

The hardening function was first evaluated by calibrating the macro-element response against the vertical load-displacement behavior of a single foundation in the FD model. Two hardening functions were examined, the first is based on the function presented by Nova and Montrasio (1991):

[14] $\frac{V_{\text {limit }}}{V_{\text {ult }}}=1-\exp \left(-\frac{R_{0} w_{p}}{V_{u l t}}\right)$

where $V_{\text {limit }}$ is the vertical limit load applied on the foundation, $V_{u l t}$ is the vertical failure load (when only vertical load is applied), $w_{p}$ is the vertical (plastic) displacement and $R_{0}$ is the initial slope of the load-settlement curve ( $R_{0}$ has units of stiffness - $\mathrm{kN} / \mathrm{m}$ ). The second is based on the function presented by Gottardi et al. (1999):

$$
\text { [15] } \quad V_{\text {limit }}=\frac{K_{p} w_{p}}{1+\left[\left(K_{p} w_{p m} / V_{u l t}\right)-2\right]\left(w_{p} / w_{p m}\right)+\left(w_{p} / w_{p m}\right)^{2}}
$$

where $K_{p}$ is the initial plastic stiffness, $w_{p}$ is the vertical plastic displacement and $w_{p m}$ is the value of $w_{p}$ at the vertical failure load $\left(V_{u l t}\right)$.

The hardening function presented by Nova and Montrasio (1991) (Eq. 14) was originally developed for a rigid-plastic constitutive law where $R_{0}$ is the initial slope of the load-displacement curve. In the current formulation, in which the behavior is elasto-plastic, the meaning of $R_{0}$ is different. Nonetheless, 
it can be shown that if $R_{0}$ is replaced by $K_{v v} \alpha /(1-\alpha)$ (where $K_{v v}$ is the elastic vertical stiffness), such that:

[16] $\quad V_{\text {limit }}\left(w^{p}\right)=V_{u l t}\left(1-\exp \left(-\frac{\frac{\alpha}{1-\alpha} K_{v v} w^{p}}{V_{u l t}}\right)\right)$

then the initial virgin loading stiffness will be equal to $\alpha K_{v v}$. Essentially, this allows evaluation of $R_{0}$ or $\alpha$ from the FD simulations by investigation of the ratio of initial virgin loading stiffness to the unloading (elastic) stiffness. Alternatively, one can search of the best $\alpha$ to fit the response in terms of plastic displacement and vertical load.

Fig. 6 shows the vertical load values obtained from the FLAC ${ }^{3 \mathrm{D}}$ analysis and the best calibrated Gottardi et al. (1999) (Eq. 15) and Nova and Montrasio (1991) (Eq. 16) models. Three curves are shown in Fig. 6: (1) Eq. 16 with $\alpha=1 / 3$ and $V_{u l t}=5885 \mathrm{kN}$ is shown as a dashed line, (2) Eq. 15 with $K_{p}=\frac{\alpha}{1-\alpha} K_{v v}, \alpha=0.45, w_{p m}=0.4 \mathrm{~m}$ and $V_{u l t}=5885 \mathrm{kN}\left(w_{p m}\right.$ and $V_{u l t}$ were taken from the FLAC $^{3 \mathrm{D}}$ results) is shown as a dotted line, and (3) $\mathrm{FLAC}^{3 \mathrm{D}}$ is shown as a continuous line. Note that $V_{u l t}$ was taken from the $\mathrm{FLAC}^{3 \mathrm{D}}$ results.

Fig. 6a shows the relationship between the vertical load, $V$, to the total displacement, $w$. The elastic vertical stiffness, $K_{v v}$, extracted from the unloading slope of the elasto-plastic FLAC ${ }^{3 \mathrm{D}}$ model gave a value of $37.4 \times 10^{4} \mathrm{kN} / \mathrm{m}$. This value is very similar to the elastic vertical stiffness extracted from the elastic model and used in the suggested formulation $\left(37.38 \times 10^{4} \mathrm{kN} / \mathrm{m}\right)$.

As can be seen in Fig. 6a, the initial loading stiffness (slope) of the $\mathrm{FLAC}^{3 \mathrm{D}}$ model is similar to the unloading slope, which means that the initial elasto-plastic stiffness is equal to the elastic stiffness. This can be associated with discretization of the FLAC ${ }^{3 \mathrm{D}}$ mesh. An infinitely small mesh discretization would have led to plastic yielding in the $\mathrm{FLAC}^{\mathrm{BD}}$ model at the initial state, considering that finer discretization would make the elastic part of the solution closer to the exact elastic solution which involves an infinite contact stress at the edge of a rigid foundation.

Fig. $6 \mathrm{~b}$ shows the results of the comparison between the calibrated hardening functions and the FD results. In this comparison, the vertical plastic displacement of FLAC ${ }^{3 D}$ is calculated using the elastic vertical stiffness (i.e. $w_{p}=w-K_{v v} \cdot V$ ). As can be seen, both Eqs. 15 and 16 exhibit fair agreement with the FLAC ${ }^{3 \mathrm{D}}$ model. Eq. 15 uses one more parameter than Eq. $16\left(w_{p m}\right)$, and provides a slightly better agreement. 

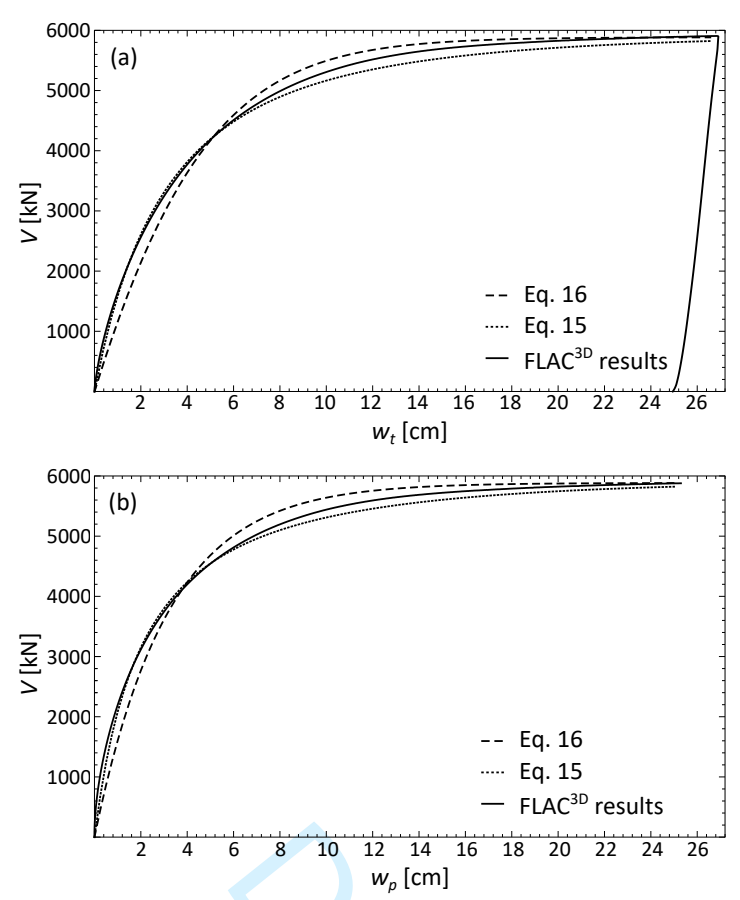

Fig. 6. Vertical load-displacement comparison between FLAC ${ }^{3 \mathrm{D}}$ and analytical models: (a) Load-total displacement relationship, (b) Load-plastic displacement relationship

\subsubsection{Interaction between the foundations}

While the solution involves all degrees of freedom, the interaction between foundations was assumed to be governed only by vertical continuum deformation. The interaction matrix was evaluated using the finite difference simulations without the tunnel. The interaction matrix was evaluated by applying vertical displacement (in the elasto-plastic model) to one of the corner foundations and calculating the vertical reaction of the same foundation and the displacements of all other foundations.

Fig. 7 shows the interaction results evaluated from the above procedure, where the horizontal axis represents the force acting on the controlled foundation and the vertical axis represents the vertical displacement of all the foundations. Each line represents a different foundation at a different distance from the controlled foundation. As can be seen, the response of the loaded (controlled) foundation is not linear, but the response of all the other foundations is roughly linear. This infers that the assumption of linear interaction between the foundations is legitimate. The interaction factors were evaluated from the slope of the lines presented in Fig. 7. 


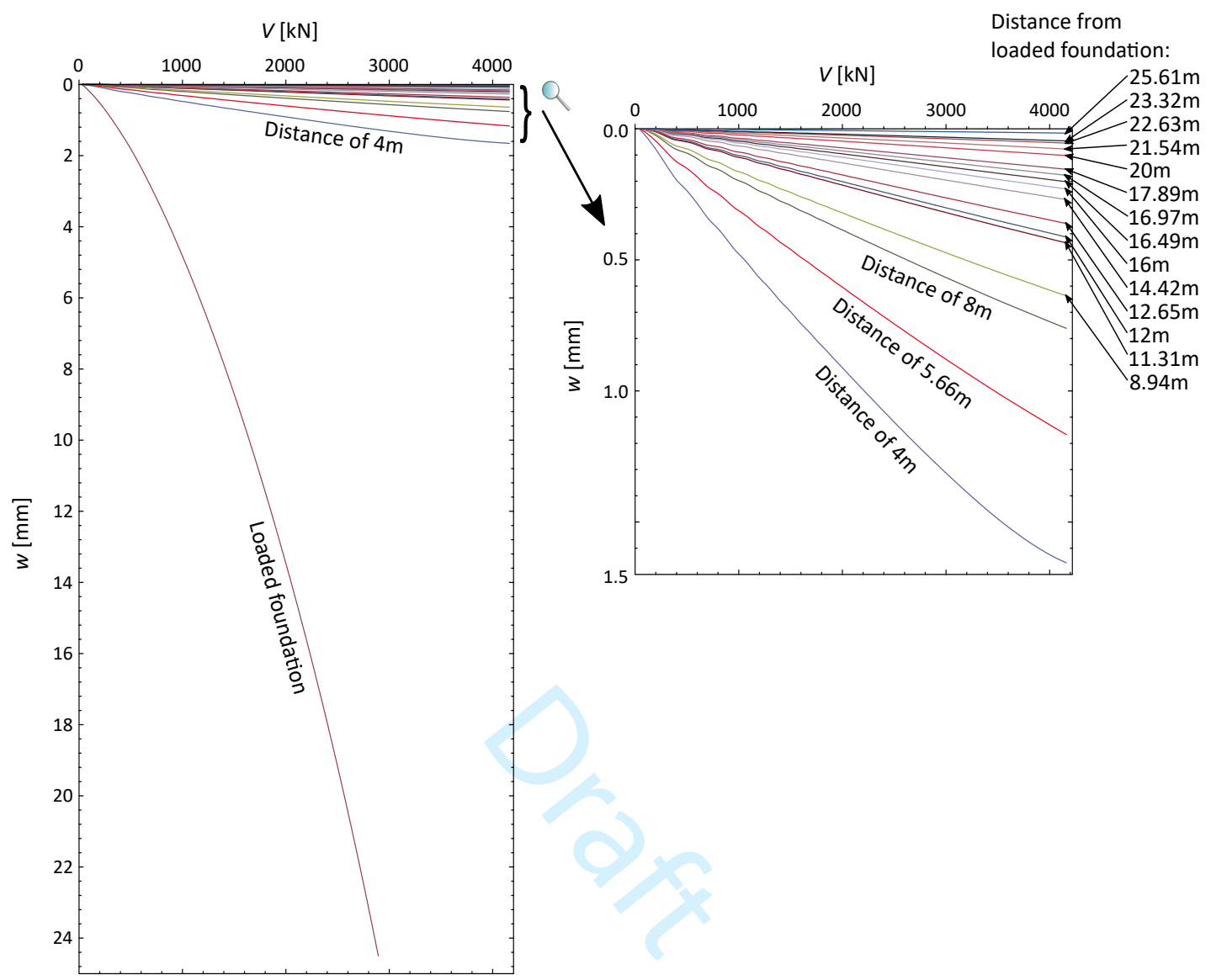

Fig. 7. Interaction results from FLAC $^{3 \mathrm{D}}$

\subsubsection{Greenfield displacement}

The greenfield displacement $\left(\left\{u^{g f}\right\}\right.$, vertical, horizontal and rotational), for the verification model, was evaluated by using the same finite difference model without the building and any foundation (i.e. free surface without controlling the foundation grid points velocity). All quantities were defined based on the average greenfield displacement within the supposed foundation area, where the rotation was defined based on the average slope relative to the center of the foundation.

\subsubsection{The yield function $f$ and plastic flow potential $g$}

The additional input required for the suggested formulation is the yield function and plastic flow potential function. The yield function, $f$, used in this work is an extension of the function presented by 
Nova and Montrasio (1991), from 3 degrees of freedom to 5:

$$
\begin{aligned}
f= & \left(\frac{H_{x}}{\mu V_{u l t}}\right)^{2}+\left(\frac{H_{y}}{\mu V_{u l t}}\right)^{2}+\left(\frac{M_{x}}{\psi B V_{u l t}}\right)^{2}+\left(\frac{M_{y}}{\psi B V_{u l t}}\right)^{2}- \\
& -\left(\frac{V}{V_{u l t}}\right)^{2}\left(1-\frac{V}{V_{\text {limit }}}\right)^{2 \beta}=0
\end{aligned}
$$

where $H_{x}$ and $H_{y}$ are the horizontal forces, $M_{x}$ and $M_{y}$ are the moments acting on the foundations, $V$ is the vertical force, $V_{\text {limit }}$ is the vertical limit load, $\beta=0.95, \mu=0.52$ and $\psi=0.35$ (as suggested by Nova and Montrasio (1991)). Note that the foundation has no resistance against torsion. The plastic flow potential function, $g$, used in this work is an extension of the function presented by Cremer et al. (2001), from 3 degrees of freedom to 5 :

$$
g=\left(\frac{H_{x}}{\kappa V_{u l t}}\right)^{2}+\left(\frac{H_{y}}{\kappa V_{u l t}}\right)^{2}+\left(\frac{M_{x}}{\xi B V_{u l t}}\right)^{2}+\left(\frac{M_{y}}{\xi B V_{u l t}}\right)^{2}+\left(\frac{V}{V_{u l t}}\right)^{2}=C
$$

where $\kappa=0.23, \xi=0.18$ and $C$ is a constant allowing the plastic flow potential to intersect the yield function at $\left\{F^{*}\right\}$.

\subsection{Verification results}

Fig. 8 shows a comparison of the vertical total displacements of the foundations before (Fig. 8a) and after (Fig. 8b) tunneling. The horizontal axis represents values from the FLAC ${ }^{3 \mathrm{D}}$ model and the vertical axis represents values from the suggested formulation. The suggested formulation results are presented for the two hardening functions provided earlier in Eqs. 14 and 15.

As can be seen in Fig. 8, the vertical displacements from the FLAC ${ }^{3 \mathrm{D}}$ model are lower than the vertical displacements obtained by the suggested formulation. One should remember that the values represent the total displacement, including the settlement of the building which existed before the tunneling process. The discrepancy between the results is associated with the effect of the hardening function on the initial stages of the simulation (i.e. on the settlement components which are relevant to the construction stage of the building). Fig. $8 \mathrm{c}$ shows a comparison of the developed vertical displacement due to the tunneling process (i.e. the final, "after tunneling", displacement minus the "before tunneling" displacement). As can be seen, the agreement is good, supporting the above reason for the discrepancy in the total displacement values. 
In order to verify that this is indeed the reason for the discrepancy, another hardening function was considered. Rather than using a predefined closed form analytical hardening function, a numerical fitted curve was defined to represent the hardening function as obtained in FLAC $^{3 \mathrm{D}}$. The fitted hardening function may be considered to be "perfect" in the sense that it does not deviate from the hardening function described in Fig. 6b as curve (3). Fig. 9 shows the comparison between the formulations when using the fitted hardening function in the suggested model. As can be seen, the agreement is good, indicating that indeed the difference originated from the hardening function and its behavior under the building construction process.

Fig. 10 shows the resultant foundation displacements due to tunneling within a central plane perpendicular to the tunnel centerline (that is, settlements, horizontal displacements and rotations of foundations 3,9,15,21,27 and 33 in Fig. 4). Note that the suggested formulation values are those obtained using the yield functions of Nova and Montrasio (1991) and Gottardi et al. (1999) (i.e. Eqs. 14 and 15) and not the modified ones aiming to explain the source of deviation from FLAC ${ }^{3 \mathrm{D}}$. Good agreement exists between the suggested approach and $\mathrm{FLAC}^{3 \mathrm{D}}$ in terms of overall settlement.

A few interesting observations can be made with respect to the deformation values compared to those of the greenfield. As can be seen, the foundation settlements are greater than those of the greenfield. This behavior is counter-intuitive to that which is known from linear elastic solutions of the problem, in which the greenfield displacements are "moderated" by the structure stiffness to result in a settlement trough 'around' the greenfield input. The source of this interesting phenomenon lies within the coupled vertical-horizontal plastic response of the foundation. It occurs due to the high stiffness of the building in the horizontal direction and the symmetry of the building with respect to the greenfield displacement profile. In this context, the direction of the plastic incremental displacement is determined by the plastic flow potential (i.e. $\Delta u_{x}^{l p}=\Lambda d g / d H_{x}$ and $\Delta u_{z}^{l p}=\Lambda d g / d V$ ), leading to $\Delta u_{z}^{l p}=\Delta u_{x}^{l p} \kappa^{2} V / H_{x}$ when considering the plastic flow potential provided in Eq. 18. This infers that yielding due to horizontal loading will add to the vertical displacement. If one considers that the horizontal displacements of the foundations themselves are negligible under a symmetric greenfield input due to the high horizontal stiffness of the building, then the majority of the greenfield horizontal displacement will transform into soil plastic horizontal displacements. Fig. 10b shows that indeed the building horizontal displacements are negligible compared to those of the greenfield. Note that the above explanation involves the assumption that the elastic horizontal soil displacements are small 
relative to the plastic displacements. A rough estimation of the magnitude of the additional vertical displacement may be obtained by using the plastic flow potential together with the displacement and force values, $u_{z}^{l p}=u_{x}^{g f} \kappa^{2} V / H_{x}$. Using this equation together with the vertical and horizontal forces on each of the foundations, associated with Fig. 10, results in a $u_{z}^{l p}$ in the range of 0.6 to $1 \mathrm{~mm}$. This range fairly agrees with the difference between the computed foundation settlement and the vertical greenfield displacement as shown in Fig. 10 (which ranges between 0.4 to $1.4 \mathrm{~mm}$ in the suggested formulation).

This phenomenon, of increase of settlement due to coupling in the yielding, is not an artificial results of the formulation, since it was also observed in the continuum simulation used for verification. It should be emphasized that linear elastic solutions cannot predict such behavior, and will always result in a settlement trough 'around' the greenfield input (i.e. the structure will only moderate the differential displacement of the greenfield).

The plastic coupling may also explain the discrepancy observed between FLAC ${ }^{3 \mathrm{D}}$ and the formulation in two external foundations ( 2 at the right and 2 at the left). The adopted plastic flow potential and the combined yield surface in the formulation, Eqs. 17 and 18, may not correspond perfectly to that developed with the global foundation response in FLAC ${ }^{3 \mathrm{D}}$, and since the discrepancy increases with $u^{g f}$, this may be observed where the greenfield horizontal displacements attain a maximal value.

Another interesting observation, apparent in Fig. 10c, is that the rotations of foundations due to tunneling are opposite to the greenfield values. This is a result of the horizontal and rotational coupling that exists in the structure itself. That is, the horizontal forces acting on the structure lead to outwards rotation away from the tunnel. This was verified using two consecutive elastic analyses in which the greenfield horizontal displacements were applied in one case and ignored in the other. This indicated that the horizontally induced horizontal forces lead to this behavior. It should also be noted that coupled plastic deformations due the combined loading may affect the rotational response, and this may explain, as before, some of the discrepancy observed between the formulations.

While the trends of behavior are similar in the FLAC ${ }^{3 \mathrm{D}}$ and the formulations, the differential settlements, which relates to tunneling induced damage, are not identical. Yet, both models provide a similar deflection ratio, $\Delta / L$, over the entire building $(0.015 \%$ and $0.017 \%)$, which is small and should not create any severe damage to the considered structure. 


\section{Parametric study}

This section presents a parametric analysis using the suggested formulation for the examination of the effect of tunneling on different frame-structure buildings. Buildings with different number of stories were considered, each of which with its corresponding structure stiffness. The effect of the excavation process, in terms of tunnel face advancement, was also examined using 3D incremental greenfield displacement fields as input.

Fig. 11 shows the considered buildings in the parametric study. The buildings are of 2 to 5 stories (i.e. 3 to 6 floors including the roof), symmetrical with 5 spans in each direction, resulting in 36 foundations. The building components are identical to those presented in section 3.1. As before, the building condensed stiffness matrix and reaction vectors were extracted using COMSOL Multiphysics (COMSOL 2008).

The elastic stiffness of the foundations, $K_{v v}, K_{h h}, K_{\theta \theta}$ and $K_{h \theta}$ (required for Eq. 13) were evaluated based on the theory of elasticity (Poulos and Davis 1974): $K_{v v}=\beta_{z} 2 G \sqrt{B L} /(1-\nu)$, $K_{h h}=\beta_{x} 2 G \sqrt{B L} /(1-\nu), K_{\theta \theta}=2 G B^{2} L / I_{\theta} /(1-\nu)$ and $K_{\theta h}=0$. All foundations had the size of $2.5 \times 2.5 \mathrm{~m}$. For square foundations $\beta_{z}=1.05, \beta_{x}=0.868$ and $I_{\theta}=3.7$. The value of $G /(1-\nu)$, involved in all of the above stiffness terms, was taken as 71.4MPa. The interaction between the foundations was based on the theory of elasticity (Davis and Selvadurai 1996):

[19] $\lambda_{v, i j}= \begin{cases}\frac{1-\nu}{2 G d^{*}} & i=j \\ \frac{1-\nu}{2 G d^{*}} \frac{2}{\pi} \arcsin \left(\frac{d^{*}}{2 \sqrt{\left(x_{i}-x_{j}\right)^{2}+\left(y_{i}-y_{j}\right)^{2}}}\right) & i \neq j\end{cases}$

where $\left(x_{i}, y_{i}\right)$ and $\left(x_{j}, y_{j}\right)$ are the coordinates of foundations $i$ and $j$ and $d^{*}$ is the equivalent diameter equal to $\beta_{z} B$. Note that interaction between foundations due to moment and horizontal forces is assumed to be negligible, and hence only vertical foundation to foundation interaction is considered. The global interaction matrix, $[\lambda]$ (used in Eq. 7), is composed of individual values of $\lambda_{v}$. The above equation also expresses the displacement of a foundation due to its own loading (i.e. $i=j$ ). However, the global interaction matrix considers only interaction between different foundations, and hence a value of zero is associated with $\lambda_{v, i i}$ in the process of constructing the interaction matrix.

The foundation bearing capacity was estimated using Meyerhof (1951), with a friction angle, $\phi$, of 
$30^{0}$ and volumetric unit weight, $\gamma$, of $20 \mathrm{kN} / \mathrm{m}^{3}$, resulting in $V_{u l t}=3183 \mathrm{kN}$. The building response was evaluated for the input of a tunnel at depth, $z_{t}$, of $15 \mathrm{~m}$, diameter, $D_{t}$, of $4 \mathrm{~m}$, and volume loss, $V_{L}$, ranging from $0.75 \%$ to $2.25 \%$, which gives maximum greenfield vertical settlements, $s_{\max }$, in the range of $5 \mathrm{~mm}$ to $15 \mathrm{~mm}$.

The yield and plastic flow potential functions used in this section are the same as presented in Section 3.3 (Eqs. 17 and 18 respectively). The hardening law used in the parametric study is the one presented by Nova and Montrasio (1991) (Eq. 14).

A gradually applied final settlement trough answering a Gaussian shape $\left(s_{v}(x)=s_{\max } \exp (-0.5\right.$ $\left.x^{2} / i^{2}\right)$, and $\left.s_{x}(x)=-x / z_{t} s_{v}(x), i=0.5 z_{t}\right)$ was considered as the greenfield input for the analysis presented in this section. Given that analytical functions describe the greenfield condition, the input for the analysis was based on the values at the center of the foundation (with rotations defined using derivatives of the vertical displacement). Defining the greenfield input using averaged values within the area of the foundation (where the rotation was defined as the averaged slope relative to the center of the foundation, as in the verification problem), resulted in practically the same values (with less than $0.5 \%$ difference). In the formulation the greenfield is applied incrementally to represent the gradual increase of volume loss (until maximum displacement).

The vertical response of foundations 3,9,15,21,27 and 33, shown in Fig. 4 are discussed. These foundations constitute the third foundation row perpendicular to the tunnel centerline of each of the buildings presented earlier. Fig. 12 shows the total vertical displacement before tunneling. As expected, greater loads (bigger buildings) lead to greater vertical displacements. Fig. 13 shows the tunneling induced displacements for each of the considered cases; i.e. the final foundation displacements minus their displacement before tunneling. As in the previous section, the resultant horizontal displacements were negligible compare to those of the greenfield, and therefore not presented.

As in the verification problem, the resultant vertical displacements are higher than those of the greenfield. This phenomenon was explained earlier, and is an outcome of the coupling between horizontal and vertical plastic flow.

The resultant deformation may be used to evaluate potential damage in the structure. This can be achieved by forcing the foundations of the structure to displace according to the values obtained by the suggested formulation. Investigating a kinematically forced field based on the frame deformation would most likely be an over-conservative approach for masonry walls, but may well be reasonable for 
damage evaluation in non-structural elements such as cladding. This can be achieved by considering a bi-linear variation of displacement within the frame planes, using the frame node values as input.

$$
\begin{aligned}
& \delta_{z}=\delta_{z 1}+\left(\delta_{z 2}-\delta_{z 1}\right) \frac{x}{L_{x}}+\left(\delta_{z 4}-\delta_{z 1}\right) \frac{z}{L_{z}}+\left(\delta_{z 1}-\delta_{z 2}+\delta_{z 3}-\delta_{z 4}\right) \frac{x z}{L_{x} L_{z}} \\
& \delta_{x}=\delta_{x 1}+\left(\delta_{x 2}-\delta_{x 1}\right) \frac{x}{L_{x}}+\left(\delta_{x 4}-\delta_{x 1}\right) \frac{z}{L_{z}}+\left(\delta_{x 1}-\delta_{x 2}+\delta_{x 3}-\delta_{x 4}\right) \frac{x z}{L_{x} L_{z}}
\end{aligned}
$$

where $\delta_{x}$ and $\delta_{z}$ are the in-plane displacements, and $\delta_{z i}$ and $\delta_{x i}$ are the displacements at the 4 corners $(i=1, . ., 4)$ as presented in Fig. 14. $L_{x}$ and $L_{z}$ are the dimensions of the rectangular plane within each frame opening.

Using the derived displacement field the maximum principal in plane strain can be evaluated.

The strains may be evaluated using the displacement derivatives as follows:

$$
\begin{aligned}
\epsilon_{z z}= & \frac{\partial \delta_{z}}{\partial z}=\left(\delta_{z 4}-\delta_{z 1}\right) \frac{1}{L_{z}}+\left(\delta_{z 1}-\delta_{z 2}+\delta_{z 3}-\delta_{z 4}\right) \frac{x}{L_{x} L_{z}} \\
\epsilon_{x x}= & \frac{\partial \delta_{x}}{\partial x}=\left(\delta_{x 2}-\delta_{x 1}\right) \frac{1}{L_{x}}+\left(\delta_{x 1}-\delta_{x 2}+\delta_{x 3}-\delta_{x 4}\right) \frac{z}{L_{x} L_{z}} \\
\epsilon_{x z}= & \frac{1}{2}\left(\frac{\partial \delta_{z}}{\partial x}+\frac{\partial \delta_{x}}{\partial z}\right)= \\
= & \frac{1}{2}\left(\left(\delta_{z 2}-\delta_{z 1}\right) \frac{1}{L_{x}}+\left(\delta_{z 1}-\delta_{z 2}+\delta_{z 3}-\delta_{z 4}\right) \frac{z}{L_{x} L_{z}}\right. \\
& \left.+\left(\delta_{x 4}-\delta_{x 1}\right) \frac{1}{L_{z}}+\left(\delta_{x 1}-\delta_{x 2}+\delta_{x 3}-\delta_{x 4}\right) \frac{x}{L_{x} L_{z}}\right)
\end{aligned}
$$

The maximum strain, which is the principal strain, can be evaluated from the in-plane strain components:

$$
\epsilon_{\max }=\frac{\epsilon_{z z}+\epsilon_{x x}}{2}+\sqrt{\frac{1}{4}\left(\epsilon_{z z}-\epsilon_{x x}\right)^{2}+\epsilon_{x z}^{2}}
$$

The above expression was used to investigate the difference between the following three analysis approaches: (1) elasto-plastic solution - based on the suggested formulation; (2) elastic solution - considering elastic soil behavior with the same elastic parameters as in the elasto-plastic solution; (3) greenfield solution - forcing the foundation displacements due to tunneling to be the greenfield displacements. The elastic solution and greenfield solution methods are commonly used by engineers, therefore, the validity of those methods to accurately predict the building damage is of interest.

Table 1 shows the maximum strain within the building, where Table 1a shows the results of the 
elasto-plastic solution, Table $1 \mathrm{~b}$ shows the results of the elastic solution, and Table 1c shows the results of the greenfield solution. Note that the maximum strain in the planes parallel to the tunnel centerline was found to be one order of magnitude smaller than the maximum strain of the planes perpendicular to the tunnel centerline (presented in the tables).

Table 1. Maximum strains $\left(\epsilon_{\max }\right)$ in the building walls $(\%)$

(a) Elasto-plastic solution

\begin{tabular}{r|cccc}
$s_{\max }$ & 5 story & 4 story & 3 story & 2 story \\
\hline $5 \mathrm{~mm}$ & 0.022 & 0.022 & 0.022 & 0.023 \\
$10 \mathrm{~mm}$ & 0.041 & 0.042 & 0.042 & 0.043 \\
$15 \mathrm{~mm}$ & 0.061 & 0.061 & 0.061 & 0.062
\end{tabular}

(b) Elastic solution

\begin{tabular}{r|cccc}
$s_{\max }$ & 5 story & 4 story & 3 story & 2 story \\
\hline $5 \mathrm{~mm}$ & 0.025 & 0.026 & 0.026 & 0.026 \\
$10 \mathrm{~mm}$ & 0.051 & 0.051 & 0.052 & 0.053 \\
$15 \mathrm{~mm}$ & 0.076 & 0.077 & 0.078 & 0.079
\end{tabular}

(c) Greenfield displacement solution

\begin{tabular}{r|cccc}
$s_{\max }$ & 5 story & 4 story & 3 story & 2 story \\
\hline $5 \mathrm{~mm}$ & 0.045 & 0.045 & 0.045 & 0.045 \\
$10 \mathrm{~mm}$ & 0.089 & 0.089 & 0.089 & 0.089 \\
$15 \mathrm{~mm}$ & 0.134 & 0.134 & 0.134 & 0.134
\end{tabular}

As can be seen, the strain levels increase with the volume loss and greenfield displacements. In the elasto-plastic and elastic solutions the differential displacements and strains decrease with stiffer buildings, although by a very small amount. This is most likely because the upper floors do not affect much the response of the foundation system. On the other hand, in the greenfield solution the displacements are, by definition, the same for all of the buildings and therefore the strains are similar. The elastic and greenfield analyses result in greater strains than those from the elasto-plastic solution, indicating that the elastic and greenfield solutions are conservative for this type (of gradually applied final settlement trough) input. Note that in the greenfield solution both the vertical and horizontal displacements were imposed on the foundation leading to excessive straining due to horizontal deformation.

The above analyses consider a gradually increased final stage. Strictly speaking, such an approach can only be considered an approximation since the elasto-plastic behavior is path dependent and the 3D tunnel excavation process may lead to a different loading path. In order to consider an advancing tunnel case, the above process was repeated with a greenfield incremental input derived from an advancing 
tunnel model incorporating the 3D settlement trough of Attewell et al. (1986). Note that the final state, generated by this $3 \mathrm{D}$ model, is the same as the Gaussian model used earlier. It was found that at the final stage the vertical displacements were marginally greater than those in the gradually increased case. With respect to straining of the planes parallel to the tunnel, it was found that the most critical state occurred when the tunnel face was positioned below the structure, leading to strains of $\epsilon_{\max }=0.013 \%$ compared with $\epsilon_{\max }=0.003 \%$ in the gradually increased case. Both strain values are smaller than those developed in the perpendicular plane to the tunnel.

The above analyses involve fairly flexible framed structures, and while the effect of stiffness appears in the number of stories of buildings, the structures can hardly be compared to stiffer structures involving infill walls. As such, further study is recommended before the above conclusions are generalized.

\section{Summary and conclusions}

A new formulation for nonlinear analysis of tunneling effects on existing buildings was presented. The suggested method allows simple communication between the structural and geotechnical engineers while including rigorous consideration of soil structure interaction and allowing for 3D modeling of the interaction problem. The formulation follows the concepts of matrix condensation for the representation of the building and the consideration of soil nonlinearity through the use of macro-elements in conjunction with interaction terms between the foundations.

The formulation was validated by comparison to elasto-plastic continuum solutions obtained by FLAC $^{3 \mathrm{D}}$. The comparison showed good agreement, indicating that the main assumptions of the formulation, associated with the continuum nature of the soil and the development of local plastic zones, are valid.

An interesting phenomenon, in which the foundation settlements are greater than those of the greenfield, was observed and discussed. It was shown that the source of this phenomenon lies within the coupled vertical-horizontal plastic response of the foundations. This behavior cannot be captured by linear elastic solutions and is a good example of the advantage of the suggested formulation.

Following the validation, the formulation was used to conduct a parametric study to evaluate the effect of tunneling on existing multi-story buildings. Maximum strains of the cladding and non-structural elements were evaluated based on three methods - the suggested elasto-plastic formulation, linear elas- 
tic solution, and greenfield solutions (i.e. forcing the foundation displacement due to tunneling to be the greenfield displacement). The analyses indicated that evaluation of the maximum strain using the elastic and greenfield methods may be too conservative, predicting strains up to $30 \%$ higher in the case of the linear elastic soil behavior and more than twice in the case of the greenfield method (most likely because of the imposed horizontal greenfield displacements).

It should be noted that the analyses presented in the paper were limited to fairly flexible framed structures and to symmetric conditions. Further work on stiff structures with infill walls, as well as cases involving offset in building position relative to the tunnel, should be performed to generalize some of the conclusions. 

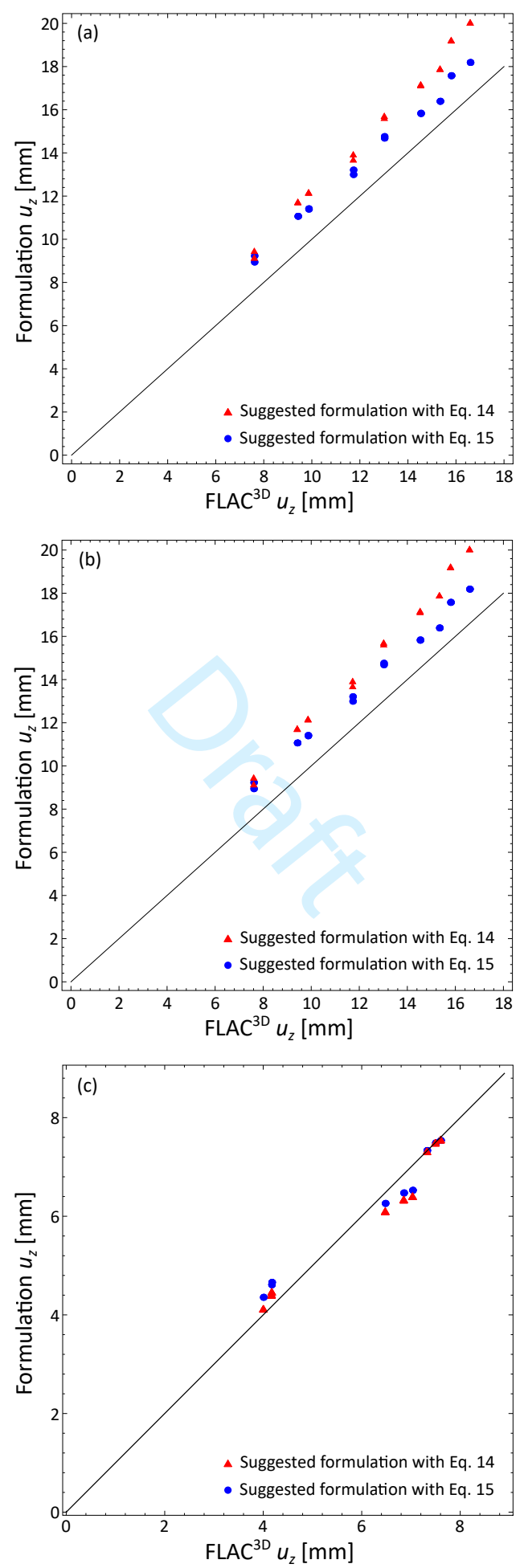

Fig. 8. Comparison of vertical displacements between FLAC ${ }^{3 \mathrm{D}}$ and the suggested formulation: (a) Before tunneling, (b) After tunneling, (c) tunneling induced vertical displacement 

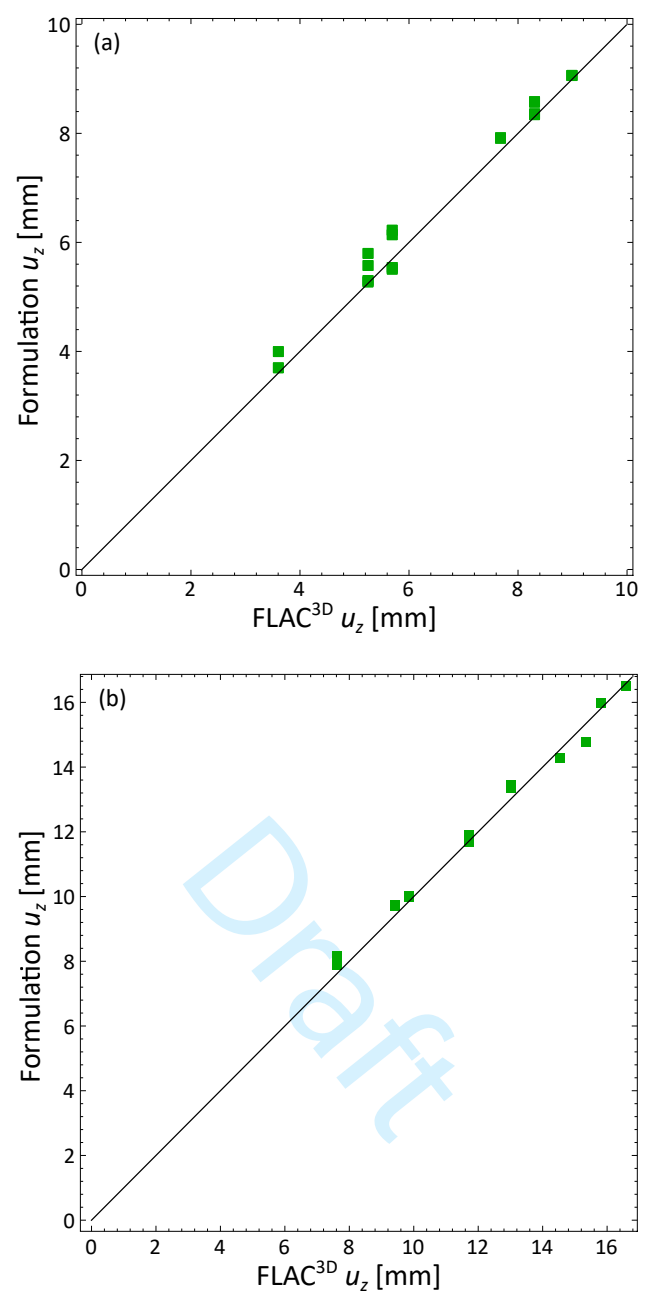

Fig. 9. Vertical displacement comparison between FLAC $^{3 \mathrm{D}}$ and formulation results with a fitted hardening function: (a) Before tunneling, (b) After tunneling 

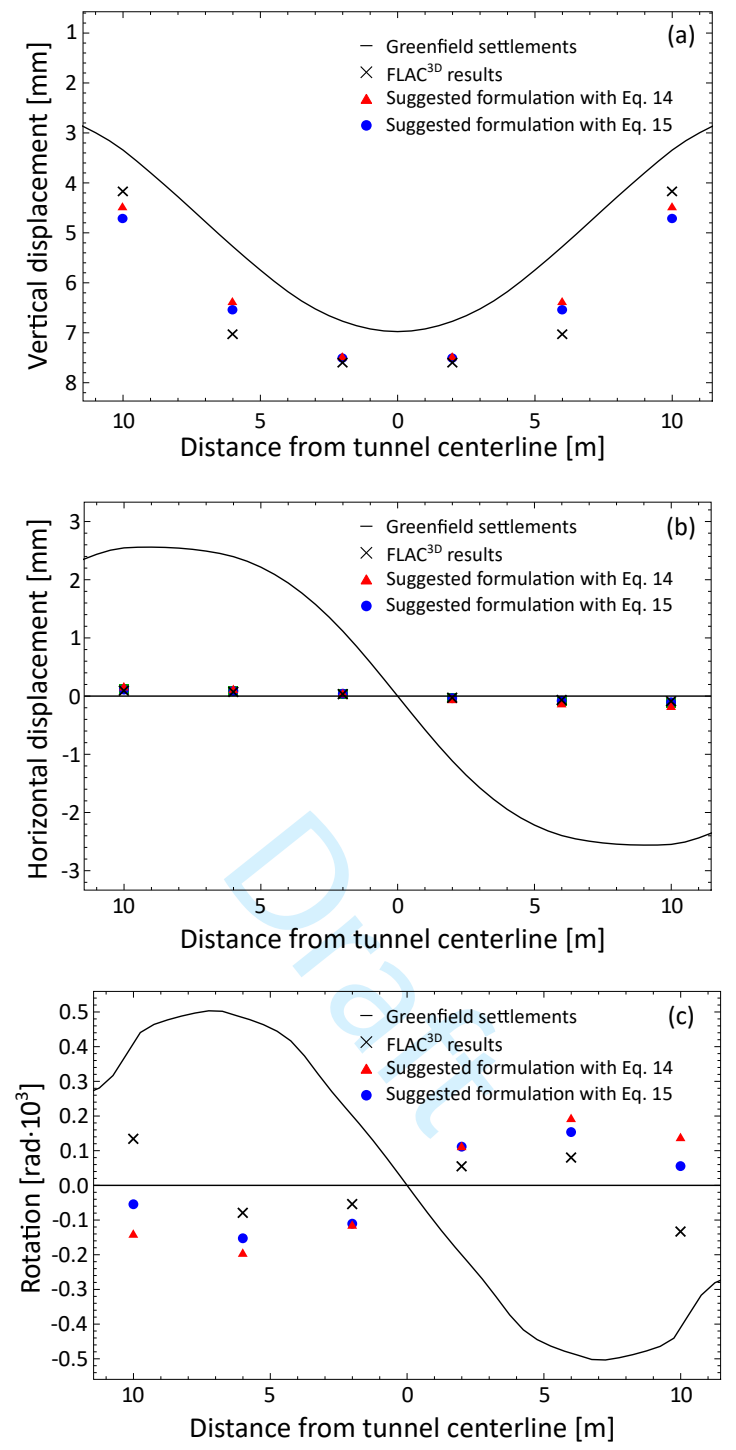

Fig. 10. Displacements due to tunneling (i.e. difference between final and before tunneling state) 
(a)



(c)

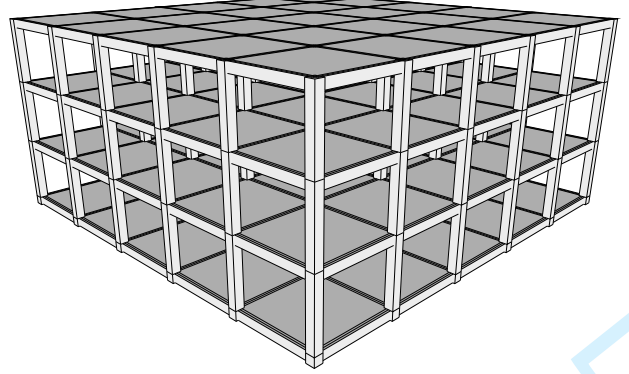

(b)

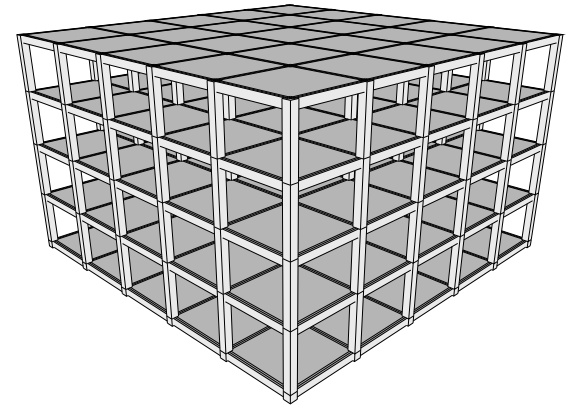

(d)

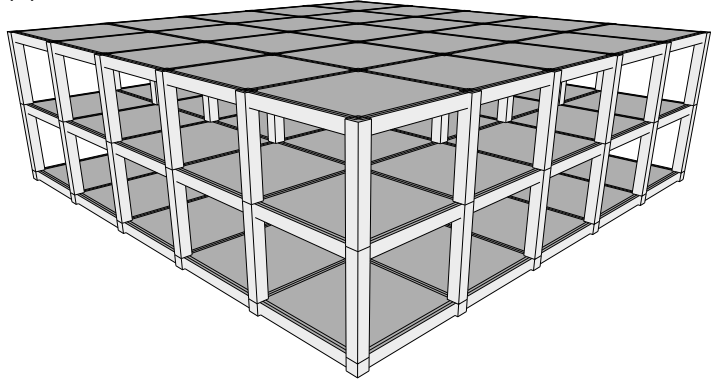

Fig. 11. The buildings used for the parametric analysis: (a) 5 story building, (b) 4 story building, (c) 3 story building, (d) 2 story building

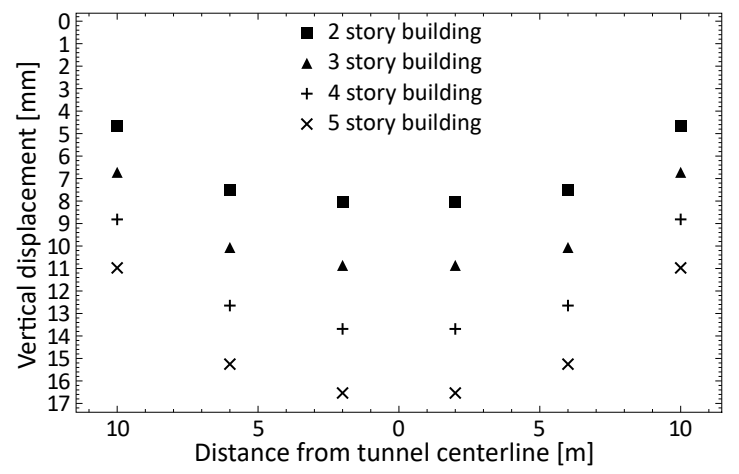

Fig. 12. Total vertical displacement before tunneling 


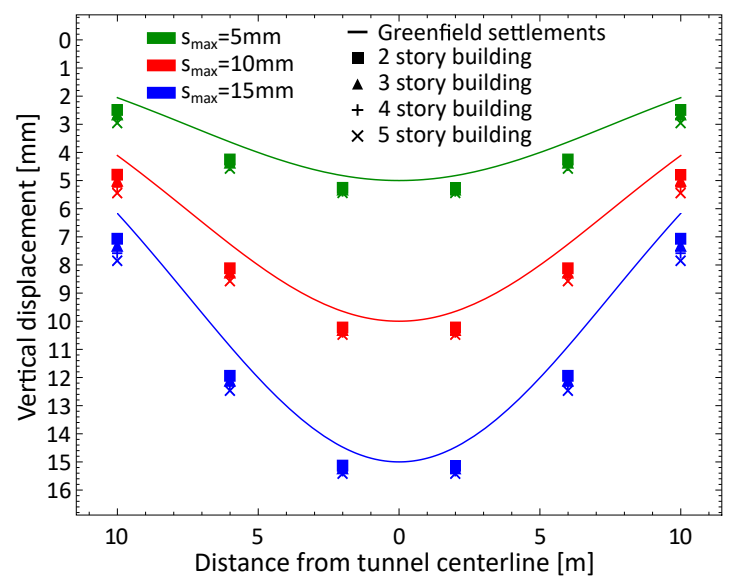

Fig. 13. Vertical displacement due to tunneling.

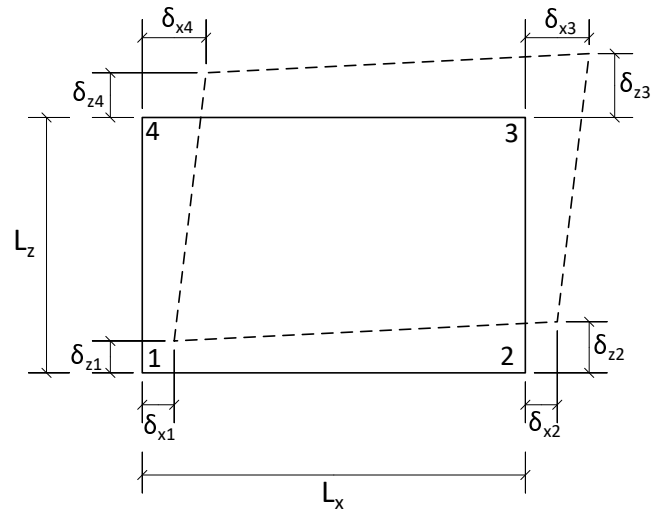

Fig. 14. Wall deformation by applying displacement at the frame corners 


\section{References}

Addenbrooke, T. I., Potts, D. M., and Puzrin, A. M. 1997. The influence of pre-failure soil stiffness on the numerical analysis of tunnel construction. Géotechnique, 47(3):693-712.

Attewell, P. B., Yeates, J., and Selby, A. R. 1986. Soil movements induced by tunnelling and their effects on pipelines and structures. Blackie and Son Ltd, London.

Burland, J. B. 1995. Assessment of risk of damage to buildings due to tunneling and excavation. In Earthquake Geotechnical Engineering, volume 3, pages 1189-1201, Tokyo.

Butterfield, R. and Gottardi, G. 1994. A complete three-dimensional failure envelope for shallow footings on sand. Géotechnique, 44(1):181-184.

COMSOL 2008. COMSOL Multiphysics Ver. 3.5. Burlington, MA, USA.

Cremer, C., Pecker, A., and Davenne, L. 2001. Cyclic macro-element for soil-structure interaction: material and geometrical non-linearities. International Journal for Numerical and Analytical Methods in Geomechanics, 25(13):1257-1284.

Davis, R. O. and Selvadurai, A. P. S. 1996. Elasticity and geomechanics. Cambridge University Press, Cambridge.

Franza, A. and DeJong, M. 2018. Elastoplastic solutions to predict tunnelling-induced load redistribution and deformation of surface structures. ASCE Journal of Geotechnical and Geoenvironmental Engineering, page under review.

Franza, A., Marshall, A. M., Haji, T., Abdelatif, A. O., Carbonari, S., and Morici, M. 2017. A simplified elastic analysis of tunnel-piled structure interaction. Tunnelling and Underground Space Technology, 61:104-121.

Franzius, J. N., Potts, D. M., and Burland, J. B. 2005. The influence of soil anisotropy and K0 on ground surface movements resulting from tunnel excavation. Géotechnique, 55(3):189-199.

Giardina, G., Hendriks, M. A., and Rots, J. G. 2015. Sensitivity study on tunnelling induced damage to a masonry façade. Engineering Structures, 89:111-129. 
Giardina, G., van de Graaf, A. V., Hendriks, M. A., Rots, J. G., and Marini, A. 2013. Numerical analysis of a masonry façade subject to tunnelling-induced settlements. Engineering Structures, 54:234-247.

Gottardi, G., Houlsby, G. T., and Butterfield, R. 1999. Plastic response of circular footings on sand under general planar loading. Géotechnique, 49(4):453-469.

Houlsby, G. T. and Cassidy, M. J. 2002. A plasticity model for the behaviour of footings on sand under combined loading. Géotechnique, 52(2):117-129.

Itasca 2011. FLAC3D Ver. 4.0- User Manual. Minneapolis, MN, USA.

Klar, A. 2018. Elastic Continuum Solution for Tunneling Effects on Buried Pipelines Using Fourier Expansion. Journal of Geotechnical and Geoenvironmental Engineering, 144(9):04018062.

Klar, A., Elkayam, I., and Marshall, A. M. 2016. Design oriented linear-equivalent approach for evaluating the effect of tunneling on pipelines. Journal of Geotechnical and Geoenvironmental Engineering, 142(1):04015062.

Klar, A. and Marshall, A. 2015. Linear elastic tunnel pipeline interaction: the existence and consequence of volume loss equality. Géotechnique, 65(9):788-792.

Klar, A., Vorster, T. E. B., Soga, K., and Mair, R. J. 2007. Elastoplastic Solution for Soil-Pipe-Tunnel Interaction. Journal of Geotechnical and Geoenvironmental Engineering, 133(7):782-792.

Leung, Y., Klar, A., Soga, K., and Hoult, N. 2017. Superstructurefoundation interaction in multiobjective pile group optimization considering settlement response. Canadian Geotechnical Journal, 54(10):1408-1420.

Loganathan, N. and Poulos, H. G. 1998. Analytical prediction for tunneling-induced ground movements in clays. Journal of Geotechnical and Geoenvironmental Engineering, 124(9):846-856.

Mair, R. J. and Taylor, R. N. 1997. Bored tunnelling in the urban environment. In 14th international conference on soil mechanics and foundation engineering, volume 4, pages 2353-2385, Hamburg.

Mair, R. J., Taylor, R. N., and Bracegirdle, A. 1993. Subsurface settlement profiles above tunnels in clays. Géotechnique, 43(2):315-320.

Published by NRC Research Press 
Marshall, A. M., Farrell, R. P., Klar, A., and Mair, R. J. 2012. Tunnels in sands: the effect of size, depth and volume loss on greenfield displacements. Géotechnique, 62(5):385-399.

Meyerhof, G. G. 1951. The Ultimate Bearing Capacity of Foudations. Géotechnique, 2(4):301-332.

Muir-Wood, D. 2004. Geotechnical Modelling. Taylor \& Francis, London.

Nova, R. and Montrasio, L. 1991. Settlements of shallow foundations on sand. Géotechnique, 41(2):243-256.

Potts, D. M. and Addenbrooke, T. I. 1997. A structure's influence on tunnelling-induced ground movements. Proceedings of the Institution of Civil Engineers: Geotechnical Engineering, 125(2):109125.

Poulos, H. G. and Davis, E. H. 1974. Elastic Solutions for Soil and Rock Mechanics. Jhon Wiley \& sons, inc, Sydney. 